\title{
Diagnostic Value of Concentration Profiles of Glucocorticosteroids and Endocannabinoids in Hair
}

\author{
Aniko Krumbholz, MSc, ${ }^{*}$ Patricia Anielski, MD, ${ }^{*}$ Nicole Reisch, MD, $\dagger$ Gustav Schelling, Prof, $\neq$ \\ and Detlef Thieme, MD*
}

Background: Endogenous corticosteroids and endocannabinoids are both known to be involved in stress adaption and anti-inflammatory and immuneregulatory effects. The application of hair as retrospective specimen for long-term recording of corticosteroids and its association with stress-induced biochemical alterations was intensively examined.

Methods: To evaluate the stability and correlation of various parameters of the endocannabinoid and corticosteroid systems, a prospective study was carried out. Hair samples were collected monthly over a pregnancy cycle (sixth week of pregnancy to 9 weeks postpartum). By comparison of hair concentrations in particular segments (ie, grown in the same time span but collected at different times), an examination of analyte stability in hair was achieved. Additionally, the comparison of proximal segments provided on biochemical information that is independent of alteration due to physical instability. The detection limits of a validated procedure using solid-phase extraction cleanup and liquid chromatography-mass spectrometry proved to be suitable to identify the endogenous levels of cortisol (limits of detection $=1.6 \mathrm{pg} / \mathrm{mg}$ ), cortisone $(2.1 \mathrm{pg} / \mathrm{mg}$ ), anandamide (AEA, $0.3 \mathrm{pg} / \mathrm{mg}$ ), and 2-arachidonoylglycerol (15 pg/mg).

Results: Corticosteroid concentrations in corresponding hair segments were found to be reduced with increasing hair age; an average decline of cortisol and cortisone by $50 \%$ in 4 months was estimated. Independently, an increase of cortisol and cortisone in proximal segments collected during pregnancy was confirmed, which is assumed to be stress related. Endocannabinoids proved to be by far more stable, as demonstrated by subsequent monthly collection of corresponding segments and there was hardly any washout of AEA detectable. Elevated hair concentrations of AEA and 2-arachidonoylglycerol were detected in the first-second trimester of pregnancy, which corresponds to negative correlations between AEA, cortisol, and cortisone.

Key Words: corticosteroids, endocannabinoids, hair, pregnancy, LC-MS/MS

(Ther Drug Monit 2013;35:600-607)

Received for publication November 26, 2012; accepted April 2, 2013.

From the *Institute of Doping Analysis and Sports Biochemistry, Dresden; $\dagger$ Endocrine Research Unit, Medizinische Klinik und Poliklinik IV, University Hospital, Munich; and †Department of Anesthesiology, Ludwig-MaximiliansUniversity, Munich, Germany.

The authors declare no conflicts of interest.

Correspondence: Aniko Krumbholz, MSc, Institute of Doping Analysis and Sports Biochemistry, Dresdner Strasse, 12, Kreischa 01731, Germany (e-mail: aniko.krumbholz@idas-kreischa.de).

Copyright (C) 2013 by Lippincott Williams \& Wilkins

\section{INTRODUCTION}

The endogenous corticosteroids cortisol and cortisone interact with various biochemical pathways, for example, fat, protein, and carbohydrate biosyntheses and metabolisms. Cortisol as a biologically active hormone is responsible for several highly important physiological actions, for example, stress adaptation and anti-inflammatory, and immuneregulatory effects. The biosynthesis of corticosteroids is affected by individual situations and circumstances (eg, acute and chronic stress exposure ${ }^{1-4}$ ). Due to its importance in several diseases, such as the Cushing Syndrome and Morbus Addison, or enzyme deficiencies, cortisol is commonly used as a diagnostic parameter. During the past years, cortisol and cortisone were discussed as biomarkers for various chronic stress situations, for example, depression ${ }^{5}$ or posttraumatic stress disorder. ${ }^{6}$ Due to the circadian fluctuation of cortisol in blood, urine, and saliva, caused by a pulsatile release and circadian rhythm, ${ }^{7}$ a single concentration value would be unfavorable. Alternatively to collection of day profiles or a consistent sampling at a certain time of the day, hair samples can be considered as cumulative specimens. A correlation between hair concentration of cortisol and chronic stress situation, for example, depression was shown in multiple studies. ${ }^{8-14}$ In contrast, Dowlati et $\mathrm{al}^{15}$ did not find any correlation of hair cortisol with depression.

In contrast to psychiatric disorders, such as depression or posttraumatic stress disorder, pregnancy represents a physiologic chronic stress situation. The blood level of cortisol increases continuously during pregnancy. The highest value was detected for the third trimester. ${ }^{16-18}$ Various studies were concerned with the question whether this increased cortisol concentration is also detectable in hair. ${ }^{19-21}$ Compared with control samples, the cortisol concentrations (measured by immunoassays) showed the highest values $(40-50 \mathrm{pg} / \mathrm{mg}$ ) in the proximal segments of hair samples correlated to the third trimester. Elevated cortisol concentrations were reported to be detectable up to 3 months after pregnancy. ${ }^{21}$

The endocannabinoid system is another stress-related mechanism in human physiology. It consists of several endogenous ligands (endocannabinoids), their receptors and various enzymes (eg, fatty acid amid hydrolase), which regulate their synthesis and degradation. The endocannabinoids are natural ligands that bind to the same receptor as delta-9-tetrahydrocannabinol, mainly the cannabinoid receptors $\mathrm{CB} 1$ and $\mathrm{CB} 2 .^{22}$ The most investigated are anandamide (AEA; arachidonoyl-ethanolamide) $)^{23,24}$ and 2-arachidonoylglycerol $(2 \mathrm{AG}){ }^{24,25}$ They are important for the regulation of 
various physiological processes, for example, the immune system and feeding behavior. Endocannabinoids are lipid signaling molecules that are synthesized on demand and rapidly deactivated resulting in a very short half-life. ${ }^{26}$ Thereby, they can quickly react to various acute situations. The endocannabinoid system plays an essential role in the regulation of the hypothalamic-pituitary-adrenal (HPA) axis, and it is therefore an important mediator in the response to stress. ${ }^{27}$ Various studies demonstrated temporary increases in AEA and $2 \mathrm{AG}$ blood concentrations when humans were exposed to acute stress situations, for example, kinetic, ${ }^{28}$ physical, ${ }^{29}$ and social stress. ${ }^{30}$ Measurements of AEA in the blood revealed concentration variations during pregnancy. ${ }^{31-33}$ In contrast to their first study, ${ }^{31}$ Lam et $\mathrm{al}^{32}$ showed that the AEA plasma concentrations remained unchanged during the first and second trimesters and increased during the last 3 months of pregnancy. Therefore, pregnancy seems to influence not only the glucocorticoid but also the endocannabinoid system.

The major response to stress in humans results from the activation of the HPA axis. Both the corticosteroid and the endocannabinoid system interact with the HPA axis. Due to stress, the hypothalamus is activated, and the synthesis of corticotrophin-releasing hormone is increased. This in turn stimulates the synthesis of corticotrophin that induces the production of cortisol in the adrenal cortex. Because of a negative feedback mechanism, cortisol effects the suppression of its own production. ${ }^{27,34,35}$ Endocannabinoids are critically involved in regulating this inhibitory mechanism. ${ }^{27}$ A recent study has suggested a negative relationship between the concentrations of plasma endocannabinoids and the activity of the HPA axis in stressed humans. ${ }^{36}$ Several studies in animals have shown that increased glucocorticoid concentrations in several stress-activated brain areas were associated with reduced AEA concentrations in these regions. ${ }^{37,38}$

In this work, a validated analytical method to detect cortisol, cortisone, AEA, and $2 \mathrm{AG}$ in hair samples is presented. Our study was carried out to determine the changes in hair concentrations of corticosteroids and endocannabinoids during a chronic stress situation and to establish a possible correlation between these 2 parameters. Pregnancy was chosen as a model of a chronic stress situation.

Hair samples were self-collected by one of the authors (P.A.) monthly during pregnancy. This prospective study was carried out from the sixth week of gestation until 2 months after childbirth. Thereby, variations of hair concentrations of corticosteroids and endocannabinoids in proximal segments could be analyzed serially during pregnancy. Moreover, the quantitation of all analytes in equivalent segments (ie, grown at the same time but collected at different times) revealed an age-dependent alteration of hair concentrations.

\section{MATERIALS AND METHODS}

\section{Chemicals, Reagents, and Reference Substances}

Solvents and chemicals used for hair extraction, alkaline hydrolysis, solid-phase extraction (SPE), and liquid chromatography with tandem mass spectrometry (LC-
MS/MS) were methanol, acetonitrile (both gradient grade, J.T.Baker, Deventer, Netherlands), water (gradient grade, Fisher scientific, Schwerte, Germany), ammonia (25\%, Chem Solute, Renningen, Germany), and potassium hydroxide pellets (85\%-90\%, VWR, Dresden, Germany). Ethylene glycol (J.T. Baker) was added to samples for reducing evaporation losses of the analytes. The high-performance liquid chromatography (HPLC) buffer solutions consist of a mixture of water/acetonitrile (A: 95/5 vol/vol; B: 5/95 vol/vol) containing 2 mmole of ammonium acetate (Merck, Darmstadt, Germany). The following reference compounds were used for calibration and validation: cortisone (Sigma, St Louis, MO); cortisol (Merck); AEA and $2 \mathrm{AG}$ (BioTrend, Zurich, Switzerland). Cortisol- $d_{4}$ (CIL, Andover, MA) and AEA-d $d_{8}$ (Cayman Chemicals, Ann Arbor, MI) were added as the internal standard (IS).

\section{Hair Samples}

A blank hair sample was collected from a 54-year-old woman. Endogenous concentrations of steroid hormones were not detectable due to longtime hair bleaching.

In the prospective study, 11 hair samples were selfcollected by one of the authors (P.A., 34 years) during her pregnancy. The first sample was taken in the sixth week of pregnancy and then every month up to 9 weeks after delivery.

Hair strands, as thick as a pencil, were carefully cut as close as possible to the scalp from a posterior vertex and were stored under dry conditions at room temperature. The hair samples were cut into 4 (or in 2 relevant cases into 5) segments, $2 \mathrm{~cm}$ each.

\section{Sample Preparation}

Due to the lack of potential sources of external contaminations, a washing procedure was not applied. Hair samples were powdered using an MM301 ball mill (Retsch, Haan, Germany; 1 minute at $30 \mathrm{~Hz}$ ), and powdered hair was weighed (range, 30-80 mg; average, $50 \mathrm{mg}$ ). After the addition of $2.5 \mathrm{ng}$ of cortisol- $d_{4}\left(d_{4}-\mathrm{C}\right)$ as IS, extraction with $2.5 \mathrm{~mL}$ methanol was carried out in an ultrasonic bath at $50^{\circ} \mathrm{C}$ for 4 hours. The liquid phase was separated after centrifugation, and $20 \mu \mathrm{L}$ of ethylene glycol was added before evaporation under nitrogen stream at $60^{\circ} \mathrm{C}$. After reconstitution with $0.5 \mathrm{~mL}$ water, the solution was transferred to SPE columns (Plexa BondElut, $3 \mathrm{~mL}, 60 \mathrm{mg}$; Agilent Technologies, Böblingen, Germany). SPE was processed by Aspec XL4 (Gilson, Middleton, WI). SPE columns were preconditioned with 3 $\mathrm{mL}$ of methanol and $1 \mathrm{~mL}$ of water. After loading, columns were washed with $2 \mathrm{~mL}$ of methanol/2\% $\mathrm{NH}_{4} \mathrm{OH}$ solution $(40 / 60 \mathrm{vol} / \mathrm{vol})$ and eluted with $2 \mathrm{~mL}$ of methanol/water (90/10 vol/vol). Hair residues from methanolic extraction were hydrolyzed with $1.5 \mathrm{~mL}$ of $0.5 \mathrm{~N} \mathrm{KOH}$ solution for 8 hours at $80^{\circ} \mathrm{C}$ after the addition of $2.5 \mathrm{ng}$ of AEA- $d_{8}\left(d_{8}\right.$-AEA) as IS. After separation of the liquid phase, another SPE cleanup was performed as described above. Extracts from both SPE runs were combined, evaporated (as described above), and reconstituted with $30 \mu \mathrm{L}$ of HPLC buffer A.

\section{Measurement by LC-MS/MS}

Chromatographic separation was operated on the LC system (Agilent Technologies1200 series) consisting of 
TABLE 1. Optimum Ionization and Fragmentation Conditions for Corticosteroids and Endocannabinoids: Q1, Q3, DP, and CE

\begin{tabular}{lcccc}
\hline Analyte & Q1 (Da) & Q3 (Da) & DP (V) & CE (eV) \\
\hline Cortisol & 363.2 & 267.1 & 90 & 27 \\
& & 309.1 & 90 & 24 \\
Cortisone & 361.2 & 163.1 & 55 & 33 \\
& & 121.1 & 55 & 43 \\
Cortisol- $d_{4}$ & 367.2 & 121.1 & 85 & 31 \\
AEA & 348.2 & 287.1 & 61 & 17 \\
& & 62.1 & 61 & 12 \\
2AG & 379.2 & 287.1 & 61 & 21 \\
& & 269.1 & 61 & 25 \\
PEA & 300.2 & 62.1 & 230 & 22 \\
& & 283 & 230 & 21 \\
OEA & 326.2 & 62.1 & 240 & 55 \\
& & 55.1 & 240 & 22 \\
SEA & 328.2 & 62.1 & 235 & 22 \\
& & 57.1 & 235 & 55 \\
AEA- $d_{8}$ & 356.2 & 294.1 & 61 & 17 \\
\hline
\end{tabular}

$\mathrm{CE}$, collision energy; $\mathrm{DP}$, declustering potential; $\mathrm{Q} 1$, precursor ion; $\mathrm{Q}$ 3, fragment ion.

a degasser, a binary pump, a column compartment, and an autosampler. A 5- $\mu \mathrm{L}$ volume of the reconstituted extract was injected onto a Hypersil Gold C18-column $(100 \times 2.1 \mathrm{~mm}, 3$ $\mu \mathrm{m}$; Thermo Fisher Scientific, Langerwehe, Germany) protected by a Zorbax Eclipse XDB-C8-fingertight guard cartridge $(2.1 \times 12.5 \mathrm{~mm}, 5 \mu \mathrm{m}$; Agilent Technologies). A flow rate of $300 \mu \mathrm{L} / \mathrm{min}$ was used. Chromatographic separation was carried out at $25^{\circ} \mathrm{C}$ with a binary mobile phase system using a linear gradient (HPLC buffer B $10 \%$ for 1 minute, $10 \%-100 \%$ for 10 minutes, $100 \%$ for 3 minutes).

Tandem mass spectrometry was carried out on a Q-Trap 5500 mass spectrometer (AB Sciex, Darmstadt, Germany) equipped with an electrospray ionization interface. The instrument was operated in the positive ionization mode at $+5500 \mathrm{~V}$ and a temperature of $550^{\circ} \mathrm{C}$. Two specific multiple reaction-monitoring transitions were optimized for all analytes (Table 1).

\section{Validation Parameters}

Validation of the method was performed according to the international guidelines using Valistat 1.0. ${ }^{39}$ Positive control samples were prepared of blank hair spiked at different concentration levels $(4-100 \mathrm{pg} / \mathrm{mg}$ for cortisone and cortisol, $1-20 \mathrm{pg} / \mathrm{mg}$ for AEA and $20-1000 \mathrm{pg} / \mathrm{mg}$ for $2 \mathrm{AG}$ ), which were processed in duplicate on 3 different days. The method was validated for the following parameters: sensitivity [limits of detection (LODs) and limits of quantification], linearity, intraday and interday precision and accuracy. Data are shown in Table 2.

\section{RESULTS}

\section{Profile of Corticosteroids} Table 3 .

Analyte concentrations of each segment are shown in

A decrease of corticosteroid concentrations was observed in all samples from proximal to distal segments. The possibility to get more information about the intraindividual magnitude of washout effects was given due to monthly sampling. Figure 1 shows a comparison of 1 particular hair segment, which was grown in September and October 2011 (second-third month of pregnancy) and collected at different times, as a model of the hair age-dependent decrease of hair concentrations. For both corticosteroids, the originally incorporated concentrations decreased by $>50 \%$ after 4 months of hair growth.

Alternatively, an individual comparison of proximal hair segments - which are subjects of moderate washout onlyshould be preferred. Evaluation of these segments collected every month shows a significant increase of the corticosteroid concentrations during pregnancy (Fig. 2). The highest concentrations of cortisol $(13.4 \mathrm{pg} / \mathrm{mg})$ and cortisone $(45.7 \mathrm{pg} / \mathrm{mg})$ were measured for the proximal segment of the sample taken at the fifth week postpartum. This hair segment reflects the time from April to May 2012, the last month of pregnancy, and the first month after delivery. Corticosteroid concentrations decreased again after childbirth (first 2-cm segment of the sample taken 9 weeks postpartum).

\section{Profile of Endocannabinoids}

In the case of our prospective study, AEA and $2 \mathrm{AG}$ values were measured (Table 3 ). AEA concentrations vary between 1.6 and $4.0 \mathrm{pg} / \mathrm{mg}$ (median: $2.6 \mathrm{pg} / \mathrm{mg}$ ). Figure 3 shows the hair age-dependent change of AEA and $2 \mathrm{AG}$ concentrations of the corresponding hair segments that reflect the period of September and October 2011. An elevation of concentrations with increasing age of hair is clearly visible for

TABLE 2. Validation Results of the LC-MS/MS Method for Measurement of Corticosteroids and Endocannabinoids

\begin{tabular}{|c|c|c|c|c|c|c|c|c|c|c|c|c|}
\hline \multirow[b]{2}{*}{ Analyte } & \multirow[b]{2}{*}[\mathbf{M}+\mathbf{H}]{$^{+}$} & \multirow{2}{*}{$\begin{array}{c}\text { Retention } \\
\text { Time } \\
\text { (min) }\end{array}$} & \multicolumn{2}{|c|}{ MS/MS } & \multirow[b]{2}{*}{$\begin{array}{c}\text { Coefficient of } \\
\text { Determination Type } \\
\end{array}$} & \multirow{2}{*}{$\frac{\text { Accuracy (\%) }}{\text { Middle* }^{*}}$} & \multicolumn{3}{|c|}{ Intraday CV (\%) } & \multicolumn{3}{|c|}{ Interday Bias (\%) } \\
\hline & & & $\begin{array}{c}\text { LOD } \\
\text { (pg/mg) }\end{array}$ & $\begin{array}{c}\text { LOQ } \\
\text { (pg/mg) }\end{array}$ & & & Low* & Middle* & High* & Low* & Middle* & High* \\
\hline Cortisol & 363.2 & 5.94 & 1.6 & 3.1 & 0.999 Linear & 88 & 18.2 & 7.1 & 3.4 & 19.6 & 8.7 & 3.2 \\
\hline Cortisone & 361.2 & 6.02 & 2.1 & 3.7 & 0.998 Linear & 105 & 7.4 & 7.0 & 3.8 & 14.6 & 7.6 & -0.6 \\
\hline AEA & 348.2 & 10.56 & 0.3 & 1.1 & 0.997 Linear & 116 & 12.4 & 7.0 & 5.0 & 19.4 & -1.3 & -1.7 \\
\hline $2 \mathrm{AG}$ & 379.2 & 11.06 & 15 & 35 & 0.989 Linear & 79 & 15.7 & 6.5 & 8.5 & 15.9 & -2.1 & -4.3 \\
\hline
\end{tabular}

*Concentration value: low, $6 \mathrm{pg} / \mathrm{mg}$ for cortisone/cortisol; $2 \mathrm{pg} / \mathrm{mg}$ for AEA; $20 \mathrm{pg} / \mathrm{mg}$ for 2AG; middle, $20 \mathrm{pg} / \mathrm{mg}$ cortisone/cortisol; $6 \mathrm{pg} / \mathrm{mg}$ for AEA; $200 \mathrm{pg} / \mathrm{mg}$ for 2AG; high, $100 \mathrm{pg} / \mathrm{mg}$ for cortisone/cortisol; $20 \mathrm{pg} / \mathrm{mg}$ for AEA; $1000 \mathrm{pg} / \mathrm{mg}$ for $2 \mathrm{AG}$

LOQ, limit of quantification. 
TABLE 3. Hair Concentrations of Corticosteroids and Endocannabinoids of the Voluntary Woman Who Took Part in the Prospective Study

\begin{tabular}{|c|c|c|c|c|c|}
\hline \multirow{2}{*}{$\begin{array}{l}\text { Sample (Time } \\
\text { of Sampling) }\end{array}$} & \multirow[b]{2}{*}{ Segment } & \multicolumn{4}{|c|}{ Hair (pg/mg) } \\
\hline & & Cortisol & Cortisone & $2 A G$ & $\overline{\text { AEA }}$ \\
\hline \multirow{4}{*}{$\begin{array}{l}\text { 1. Sixth week of } \\
\text { pregnancy }\end{array}$} & 1 & 5.1 & 14.6 & 266.9 & 1.9 \\
\hline & 2 & 3.9 & 11.1 & 260.1 & 1.7 \\
\hline & 3 & 2.9 & 6.9 & 261.4 & 1.7 \\
\hline & 4 & $<\mathrm{LOD}$ & 5.5 & 432.5 & 1.9 \\
\hline \multirow{4}{*}{$\begin{array}{l}\text { 2. } 12 \text { th Week of } \\
\text { pregnancy }\end{array}$} & 1 & 4.5 & 19.7 & 518.0 & 2.6 \\
\hline & 2 & 3.8 & 11.9 & 495.7 & 3.3 \\
\hline & 3 & 4.2 & 6.0 & 400.2 & 2.9 \\
\hline & 4 & $<\mathrm{LOD}$ & 5.4 & 580.0 & 3.0 \\
\hline \multirow{4}{*}{$\begin{array}{l}\text { 3. } 17 \text { th Week of } \\
\text { pregnancy }\end{array}$} & 1 & 6.2 & 20.0 & 444.6 & 2.7 \\
\hline & 2 & 4.6 & 10.8 & 762.4 & 4.0 \\
\hline & 3 & 2.8 & 7.5 & 701.8 & 3.7 \\
\hline & 4 & 1.9 & 4.7 & 646.6 & 3.0 \\
\hline \multirow{4}{*}{$\begin{array}{l}\text { 4. } 21 \text { st Week of } \\
\text { pregnancy }\end{array}$} & 1 & 5.2 & 19.8 & 330.2 & 2.5 \\
\hline & 2 & 2.1 & 10.8 & 701.4 & 3.0 \\
\hline & 3 & $<\mathrm{LOD}$ & 7.0 & 715.2 & 2.8 \\
\hline & 4 & $<\mathrm{LOD}$ & 4.0 & 566.7 & 2.9 \\
\hline \multirow{4}{*}{$\begin{array}{l}\text { 5. } 25 \text { th Week of } \\
\text { pregnancy }\end{array}$} & 1 & 6.0 & 23.1 & 374.4 & 2.0 \\
\hline & 2 & 4.5 & 13.2 & 644.3 & 2.6 \\
\hline & 3 & 3.4 & 8.4 & 888.3 & 2.7 \\
\hline & 4 & $<\mathrm{LOD}$ & 7.1 & 655.3 & 2.8 \\
\hline \multirow{4}{*}{$\begin{array}{l}\text { 6. 30th Week of } \\
\text { pregnancy }\end{array}$} & 1 & 6.9 & 24.8 & 326.4 & 1.9 \\
\hline & 2 & 4.8 & 17.3 & 604.2 & 2.5 \\
\hline & 3 & 4.1 & 9.3 & 812.9 & 3.1 \\
\hline & 4 & $<\mathrm{LOD}$ & 5.7 & 702.8 & 2.8 \\
\hline \multirow{4}{*}{$\begin{array}{l}\text { 7. } 34 \text { th Week of } \\
\text { pregnancy }\end{array}$} & 1 & 7.4 & 29.6 & 356.4 & 1.7 \\
\hline & 2 & 4.5 & 16.6 & 662.8 & 2.6 \\
\hline & 3 & 3.6 & 9.8 & 782.4 & 2.9 \\
\hline & 4 & $<\mathrm{LOD}$ & 5.5 & 650.4 & $<\mathrm{LOD}$ \\
\hline \multirow{4}{*}{$\begin{array}{l}\text { 8. 38th Week of } \\
\text { pregnancy }\end{array}$} & 1 & 4.9 & 30.6 & 332.9 & 1.9 \\
\hline & 2 & 5.3 & 22.5 & 494.0 & 2.3 \\
\hline & 3 & 3.1 & 13.6 & 681.6 & 2.9 \\
\hline & 4 & $<\mathrm{LOD}$ & 9.4 & 806.8 & 2.2 \\
\hline \multirow{4}{*}{$\begin{array}{l}\text { 9. First week } \\
\text { postpartum }\end{array}$} & 1 & 8.7 & 39.6 & 434.8 & 1.6 \\
\hline & 2 & 6.1 & 22.1 & 635.8 & 2.4 \\
\hline & 3 & 4.0 & 13.8 & 787.4 & 2.0 \\
\hline & 4 & $<\mathrm{LOD}$ & 7.6 & 934.2 & $<\mathrm{LOD}$ \\
\hline \multirow{5}{*}{$\begin{array}{l}\text { 10. Fifth week } \\
\text { postpartum }\end{array}$} & 1 & 13.4 & 45.7 & 365.2 & 2.0 \\
\hline & 2 & 7.0 & 28.7 & 635.6 & 1.8 \\
\hline & 3 & 5.3 & 17.4 & 1106.7 & 2.1 \\
\hline & 4 & $<\mathrm{LOD}$ & 10.2 & 911.4 & 2.1 \\
\hline & 5 & $<\mathrm{LOD}$ & 7.5 & 592.2 & 1.9 \\
\hline \multirow{5}{*}{$\begin{array}{l}\text { 11. Ninth week } \\
\text { postpartum }\end{array}$} & 1 & 8.8 & 27.6 & 256.6 & 2.1 \\
\hline & 2 & 7.3 & 27.8 & 477.2 & 2.7 \\
\hline & 3 & 3.8 & 16.8 & 699.3 & 3.4 \\
\hline & 4 & $<\mathrm{LOD}$ & 9.0 & 816.1 & 2.7 \\
\hline & 5 & $<$ LOD & 6.8 & 768.1 & 2.9 \\
\hline
\end{tabular}

2AG. In contrast, AEA concentrations remained constant and did not change during the aging of hair.

AEA and $2 \mathrm{AG}$ concentrations in proximal segments grown in the first to second trimester of pregnancy tend to be increased (Fig. 4). The value of $2 \mathrm{AG}$ increases by $100 \%$ for

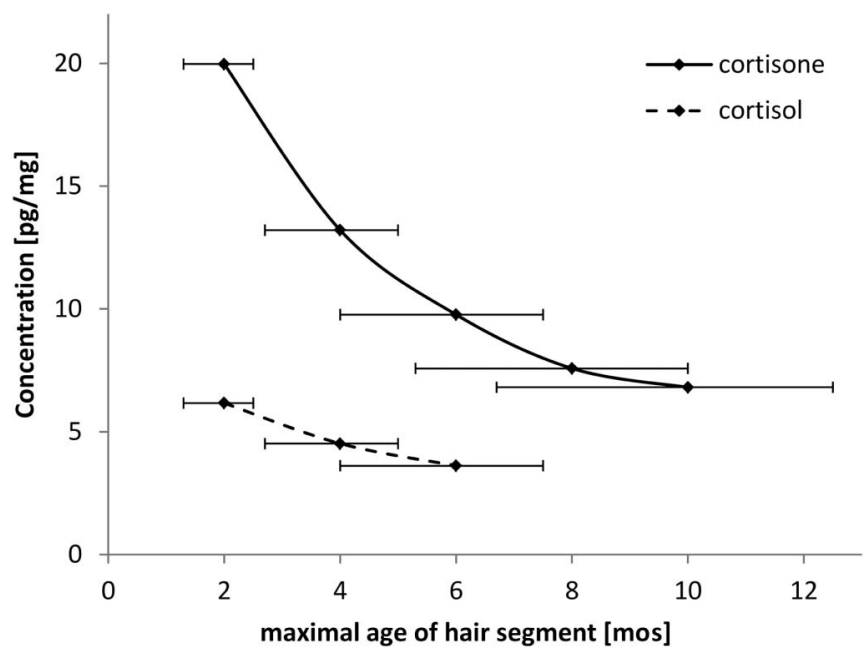

FIGURE 1. Changes of the corticosteroid concentrations in corresponding hair segments, which were grown in the same time span (September to October 2011). Sampling was accomplished every other month, and an offset of $2 \mathrm{~cm}$ was applied to select corresponding growth cycles, an average of $1 \mathrm{~cm} / \mathrm{mo}$ was assumed. The confidence intervals show the consequence of an altered hair growth (range, $0.8-1.5 \mathrm{~cm} / \mathrm{mo}$ ). The significant reduction of steroid concentrations in equivalent segments indicates the washout of cortisol and cortisone, respectively.

the first month of pregnancy and returned to the baseline levels at the end of pregnancy.

In addition, the endocannabinoids $N$-palmitoylethanolamine (PEA), $N$-oleoylethanolamine (OEA), and $N$-stearoylethanolamine (SEA) were monitored. Their hair

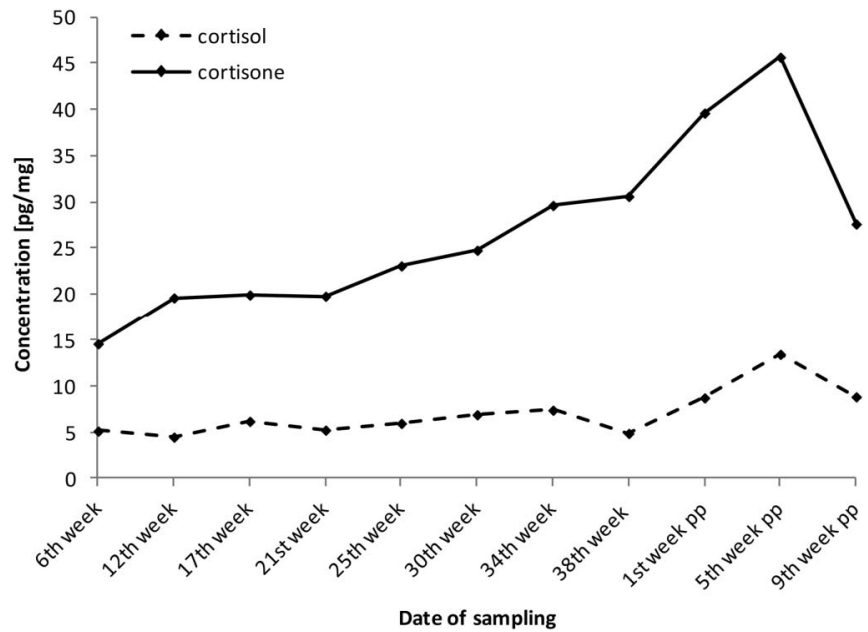

FIGURE 2. Cortisol and cortisone concentrations of the proximal segments of all hair samples taken monthly and collected during pregnancy. Each segment has a length of $2 \mathrm{~cm}$ and reflects the average of the previous 2 months, 1 month overlapping with the previous and subsequent sample. Concentration increase toward the end of pregnancy can clearly be seen. After childbirth [sample which was taken 9 weeks postpartum (pp)], the corticoid concentrations decrease again. 


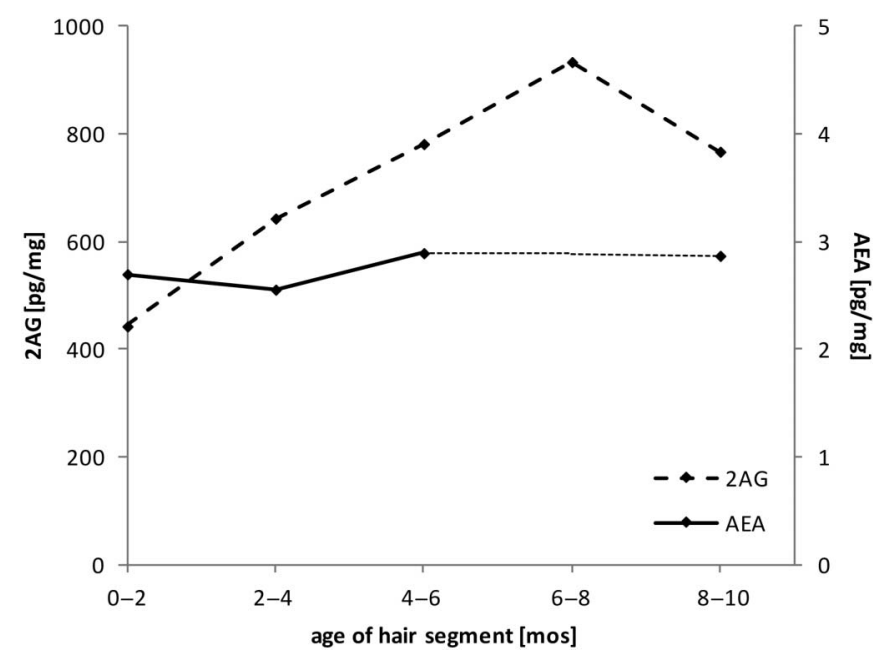

FIGURE 3. Changes of endocannabinoid concentrations in corresponding hair segments (grown in September and October 2011) after various hair growth times. 2AG shows in general an increase with increasing age, whereas the AEA levels do not change with the aging of hair.

concentrations were found to be 2-3 decades larger than that of AEA, and strong mutual correlations between concentrations of PEA, OEA, and AEA $(P<0.001)$ but no correlation between SEA and AEA (Fig. 5) exist.

\section{Correlation of Corticosteroids and Endocannabinoids}

Negative correlations $(P<0.001)$ between AEA and cortisol and cortisone are visible for the hair samples of

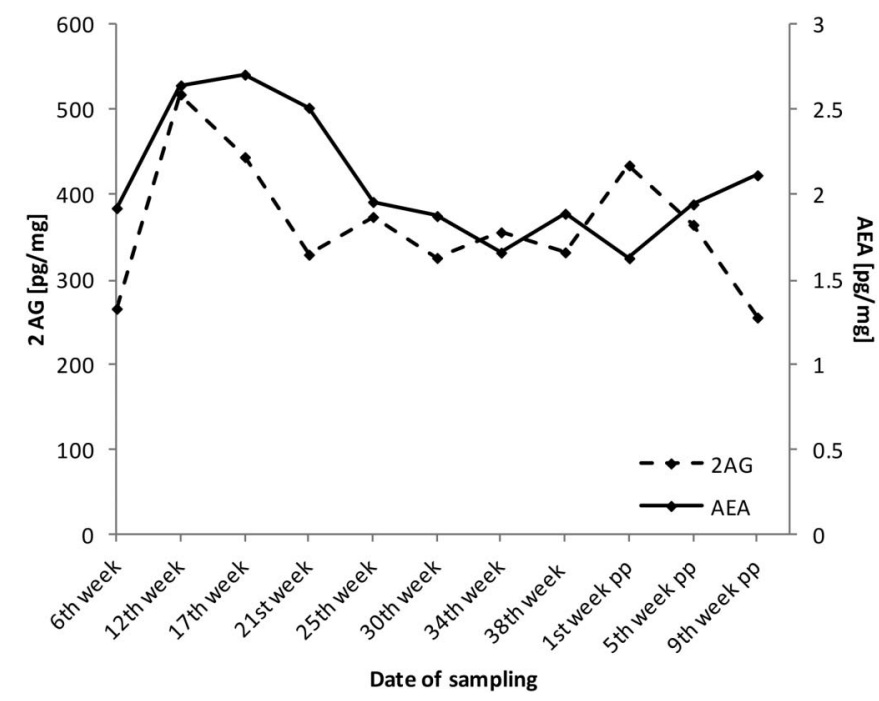

FIGURE 4. AEA and $2 A G$ concentrations of the proximal segments of all 11 hair samples taken during pregnancy. Each segment has a length of $2 \mathrm{~cm}$ reflecting the last 2 months before sampling with monthly overlapping. AEA and 2AG tend to be increased at the second trimester of pregnancy. pp, postpartum.

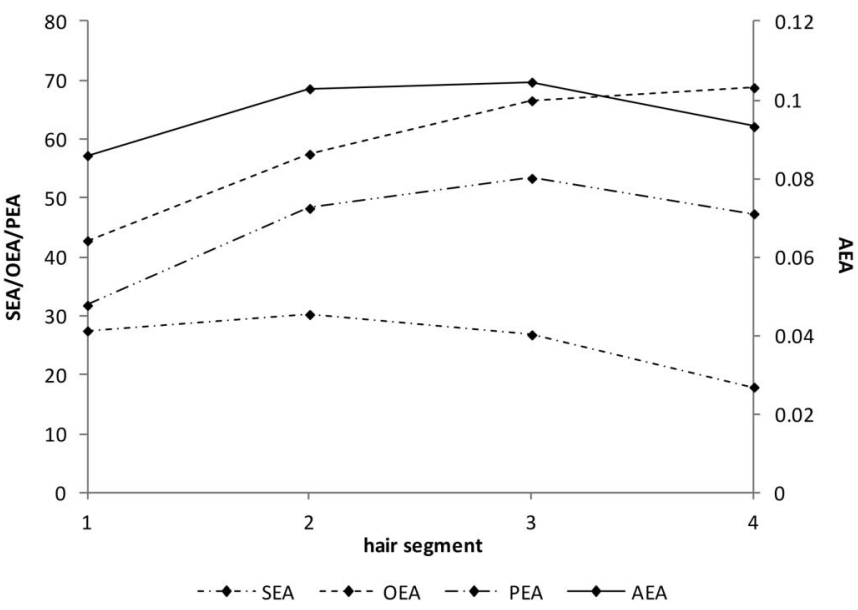

FIGURE 5. Mean hair profile of the endocannabinoids AEA, PEA, SEA, and OEA. Shown are the area ratios to the IS. AEA is 2-3 decades lower than are the other endocannabinoids. A strong correlation exists between PEA and OEA $(r=0.858)$ and PEA and $\operatorname{AEA}(r=0.692)$.

our prospective study. Also, a weak negative correlation $(P<0.01)$ can be shown between $2 \mathrm{AG}$ and the corticosteroids (Figs. 6A, B).

\section{DISCUSSION}

Based on the variations of analyte concentrations along the hair shaft this study was designed to provide a separate evaluation of the effects of washout and physiological changes due to pregnancy on the hair concentrations of corticosteroids and endocannabinoids. Conclusions from two different points of view were possible by monthly sampling.

1. At first, comparisons of selected hair segments, which were grown in a specific time and taken after different periods of growth, became available. Thereby the washout could be evaluated.

2. Second, the comparison of the proximal hair segments during pregnancy demonstrated the physiological effects.

According to our previous experiments, a decrease of corticosteroid concentrations along the hair shaft was observed in our prospective study. During our routine analysis, cortisol and cortisone were proved in $91 \%$ of the cases. Three $3-\mathrm{cm}$ segments were analyzed, and the corticosteroid concentrations were reduced between adjacent segments. The cortisol decrease was 37\% (median; range, $5 \%$ $73 \%$ ) from the proximal to the second segment and $41 \%$ (median; range, $4 \%-71 \%$ ) from the second to the third segment. The cortisone concentrations reduced by $41 \%$ (median; range, $16 \%-74 \%$ ) and by $48 \%$ (median; range, $23 \%-76 \%$ ) between contiguous segments. These decreasing concentrations along the hair strand are assumed to be mainly the consequence of a washout effect. Due to the lack of an alkaline function in the molecules, cortisol and cortisone are not able to bind to the hair pigment melanin located in the cortex (for details, see Refs ${ }^{40-42}$ ). Consequently, a loss of the 

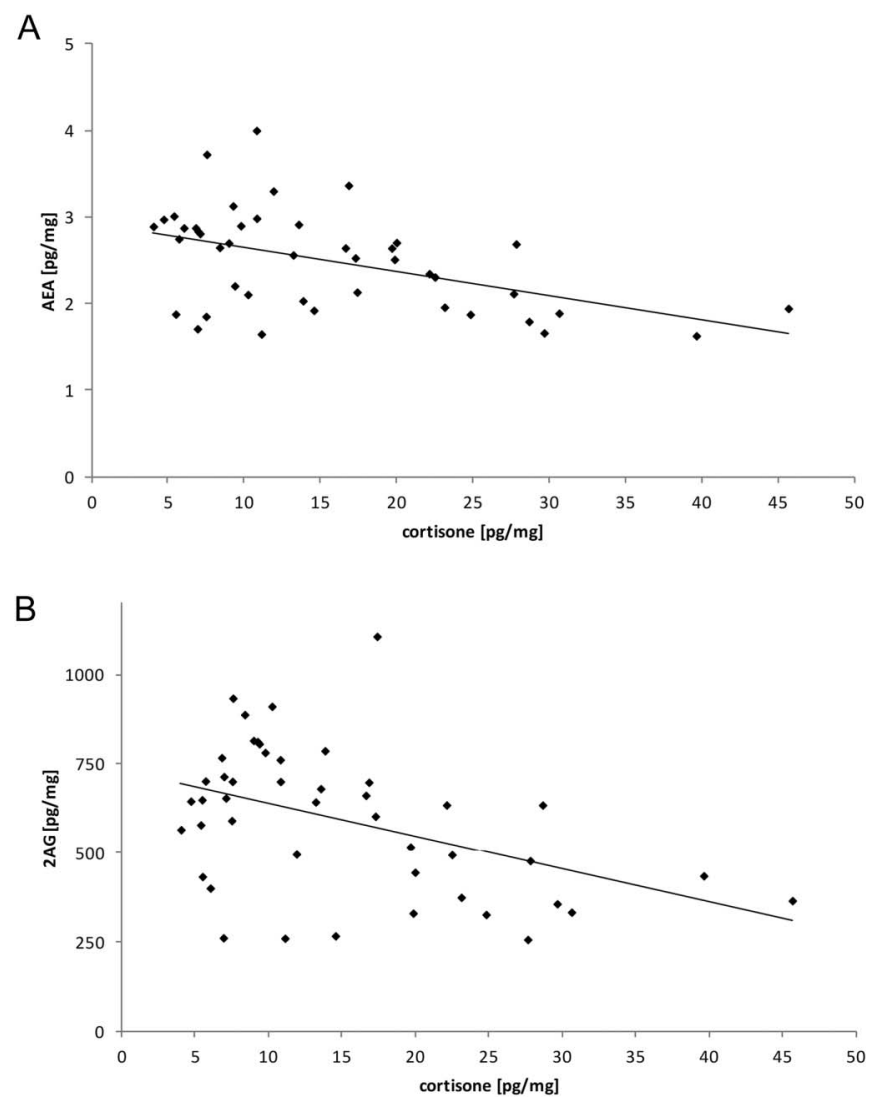

FIGURE 6. Correlations of the hair concentrations of cortisone with AEA and 2AG for the voluntary female during our prospective study. A negative correlation exists between the hair concentrations of cortisone and AEA $(6 \mathrm{~A} ; r=-0.54)$ and also between cortisone and 2AG $(6 \mathrm{~B} ; r=-0.44)$.

substances may occur by washout effects, for example, cosmetic treatment (permanent waving, dyeing), or leaching out caused by mechanical damages of the hair structure. ${ }^{43,44}$ The washout was also observed by several others ${ }^{9,19,21,45}$ but not by all $^{46,47}$ groups. Manenschijn et $\mathrm{al}^{46}$ assumed that washout of steroids results from hair sample decontamination steps before analysis. Opposed to this assumption, our studies show that a decrease of corticosteroid concentration from distal to proximal hair segment is also present without a decontamination step during sample preparation. Therefore, it seems to be an effect due to aging of hair.

Moreover, it is apparently not possible to differentiate between variations caused by washout effects and biochemical influences, for example, increase of corticosteroids due to stress based on a single sampling. The monthly sampling permitted to monitor corticoid concentrations of hair segments for a longer growth period. The older the respective hair segment, the lower the detectable concentration of the corticosteroids. In the case of prospective study, the concentrations have a half-time of approximately 4 months. According to selfreport, the hair washing did not change during the course of the study. Therefore, the intensity of the washout seems to be specific for this test person. Due to large interindividual variations of the washout effect, it is not possible to calculate the universal value for the significance, but the washout effect should be taken into consideration when retrospective statements are given.

The endocannabinoids show a different dependence on the hair aging. The AEA concentrations seem to be unaffected and stable. In consequence of the basic character (amid group) of AEA, a stronger binding to the hair pigment melanin is likely. Additional adsorption of AEA, for example, by sebum or sweat, and washout, has only little influence on the hair concentration. With regard to changes in $2 \mathrm{AG}$ concentrations, our findings were different, however. The older the respective hair segment, the higher the detectable $2 \mathrm{AG}$ concentration. This suggests that $2 \mathrm{AG}$ (similar to fatty acid ethyl esters ${ }^{48}$ ) is partially incorporated into the hair via passive diffusion from sebum or sweat.

The comparison of the proximal hair segments shows the concentration changes were due to the physiological variations during pregnancy. An increased concentration of corticosteroids is clearly visible for the last months of pregnancy and the first time after delivery. This concentration profile is presumably the result of a chronic stress situation during this time. According to other researchers, ${ }^{19-21}$ our results confirmed that this changed physiology is detectable by consecutive hair tests.

Biochemical interactions of the corticosteroid and the endocannabinoid system exist in human physiology. It was assumed that the hair profiles of both analyte groups may reflect the blood concentrations. An increase of AEA and $2 \mathrm{AG}$ was observed in the second trimester of pregnancy, which shows the negative correlation to the corticosteroids. It is conspicuous that the concentrations of the other endocannabinoids are higher than that of the AEA. This is in contrast to typical plasma concentration ratios. Therefore, a local production in skin and/or predominant hair incorporation via sweat and sebum seems to be likely.

\section{CONCLUSIONS}

Concentrations of several mediators of the corticosteroid and endocannabinoid systems in hair were examined aiming to investigate their suitability for retrospective longterm evaluations. In particular, their stability changes over time during a stressful period in life, and potential correlation between both systems were investigated.

The decrease of cortisol and cortisone concentrations from proximal to distal segments of a hair strand, which is mainly due to washout effects, is assumed to be a confounding phenomenon. This was observed in a prospective study, which allowed the subsequent examination of 1 particular hair segment after 2, 4, 6, 8, and 10 months of growing. This washout of corticosteroids is the subject of interindividual variations and can - similarly to other neutral compounds, endogenous steroids (androstenedione, testosterone), or polar compounds (ethyl glucuronide)-hardly be compensated or normalized.

Limiting measurements to proximal $(0-3 \mathrm{~cm})$ hair segments is essential to circumvent this problem and permits the quantification of systematic (eg, stress-induced) long-term variations. 
The endocannabinoids AEA and 2AG are other potent markers for stress or inflammation, and serum concentrations have been shown to reflect these conditions. ${ }^{49}$ However, their interaction and correlation with corticosteroids are not fully understood. The potential advantages of using hair to quantify endocannabinoids are retrospection and stability. Endocannabinoids, which are easily hydrolyzed in blood and require considerable analytical effort, seem to be rather stable in hair. In particular, AEA seem to be unaffected by physical alterations, for example, washout or passive adsorption. They could therefore be considered as potential complementary markers for biochemical long-term effects. An increase of AEA and 2AG in the second trimester of pregnancy was observed in the prospective study. However, additional parameters with potential influence on endocannabinoids, for example, nutrition, inflammation, and drug effects need to be taken into account.

\section{ACKNOWLEDGMENTS}

The study was supported through research funds granted by the German Federal Ministry of the Interior (BMI).

\section{REFERENCES}

1. Armario A, Marti O, Molina T, et al. Acute stress markers in humans: response of plasma glucose, cortisol and prolactin to two examinations differing in the anxiety they provoke. Psychoneuroendocrinology. 1996; $21: 17-24$

2. Dlugos A, Childs E, Stuhr KL, et al. Acute stress increases circulating anandamide and other $N$-acylethanolamines in healthy humans. Neuropsychopharmacology. 2012;37:2416-2427.

3. Meyerhoff JL, Oleshansky MA, Mougey EH. Psychologic stress increases plasma levels of prolactin, cortisol, and POMC-derived peptides in man. Psychosom Med. 1988;50:295-303.

4. Schedlowski M, Wiechert D, Wagner TO, et al. Acute psychological stress increases plasma levels of cortisol, prolactin and TSH. Life Sci. 1992;50:1201-1205.

5. Zunszain PA, Anacker C, Cattaneo A, et al. Glucocorticoids, cytokines and brain abnormalities in depression. Prog Neuropsychopharmacol Biol Psychiatry. 2011;35:722-729.

6. Simeon D, Knutelska M, Yehuda R, et al. Hypothalamic-pituitaryadrenal axis function in dissociative disorders, post-traumatic stress disorder, and healthy volunteers. Biol Psychiatry. 2007;61:966-973.

7. Weitzman ED, Fukushima D, Nogeire C, et al. Twenty-four hour pattern of the episodic secretion of cortisol in normal subjects. J Clin Endocrinol Metab. 1971;33:14-22.

8. Dettenborn L, Muhtz C, Skoluda N, et al. Introducing a novel method to assess cumulative steroid concentrations: increased hair cortisol concentrations over 6 months in medicated patients with depression. Stress. 2012;15:348-353.

9. Dettenborn L, Tietze A, Bruckner F, et al. Higher cortisol content in hair among long-term unemployed individuals compared to controls. Psychoneuroendocrinology. 2010;35:1404-1409.

10. Karlen J, Ludvigsson J, Frostell A, et al. Cortisol in hair measured in young adults - a biomarker of major life stressors? BMC Clin Pathol. 2011;11:12.

11. Skoluda N, Dettenborn L, Stalder T, et al. Elevated hair cortisol concentrations in endurance athletes. Psychoneuroendocrinology. 2012;37:611-617.

12. Steudte S, Stalder T, Dettenborn L, et al. Decreased hair cortisol concentrations in generalised anxiety disorder. Psychiatry Res. 2011;186: 310-314.

13. Van Uum SH, Sauve B, Fraser LA, et al. Elevated content of cortisol in hair of patients with severe chronic pain: a novel biomarker for stress. Stress. 2008;11:483-488.
14. Yamada J, Stevens B, de Silva N, et al. Hair cortisol as a potential biologic marker of chronic stress in hospitalized neonates. Neonatology. 2007;92:42-49.

15. Dowlati Y, Herrmann N, Swardfager W, et al. Relationship between hair cortisol concentrations and depressive symptoms in patients with coronary artery disease. Neuropsychiatr Dis Treat. 2010;6:393-400.

16. Abou-Samra AB, Pugeat M, Dechaud H, et al. Increased plasma concentration of N-terminal beta-lipotrophin and unbound cortisol during pregnancy. Clin Endocrinol (Oxf). 1984;20:221-228.

17. Carr BR, Parker CR Jr, Madden JD, et al. Maternal plasma adrenocorticotropin and cortisol relationships throughout human pregnancy. Am J Obstet Gynecol. 1981;139:416-422.

18. Mastorakos G, Ilias I. Maternal hypothalamic-pituitary-adrenal axis in pregnancy and the postpartum period. Postpartum-related disorders. Ann N Y Acad Sci. 2000;900:95-106.

19. D'Anna-Hernandez KL, Ross RG, Natvig CL, et al. Hair cortisol levels as a retrospective marker of hypothalamic-pituitary axis activity throughout pregnancy: comparison to salivary cortisol. Physiol Behav. 2011;104: 348-353.

20. Kalra S, Einarson A, Karaskov T, et al. The relationship between stress and hair cortisol in healthy pregnant women. Clin Invest Med. 2007;30: E103-E107.

21. Kirschbaum C, Tietze A, Skoluda N, et al. Hair as a retrospective calendar of cortisol production-increased cortisol incorporation into hair in the third trimester of pregnancy. Psychoneuroendocrinology. 2009;34: 32-37.

22. Pertwee RG, Howlett AC, Abood ME, et al. International Union of Basic and Clinical Pharmacology. LXXIX. Cannabinoid receptors and their ligands: beyond $\mathrm{CB}(1)$ and $\mathrm{CB}(2)$. Pharmacol Rev. 2010;62:588-631.

23. Devane WA, Hanus L, Breuer A, et al. Isolation and structure of a brain constituent that binds to the cannabinoid receptor. Science. 1992;258: 1946-1949.

24. Okamoto Y, Morishita J, Tsuboi K, et al. Molecular characterization of a phospholipase D generating anandamide and its congeners. $J$ Biol Chem. 2004;279:5298-5305.

25. Mechoulam R, Ben-Shabat S, Hanus L, et al. Identification of an endogenous 2-monoglyceride, present in canine gut, that binds to cannabinoid receptors. Biochem Pharmacol. 1995;50:83-90.

26. Kano M, Ohno-Shosaku T, Hashimotodani Y, et al. Endocannabinoidmediated control of synaptic transmission. Physiol Rev. 2009;89: 309-380.

27. Evanson NK, Tasker JG, Hill MN, et al. Fast feedback inhibition of the HPA axis by glucocorticoids is mediated by endocannabinoid signaling. Endocrinology. 2010;151:4811-4819.

28. Strewe C, Feuerecker M, Nichiporuk I, et al. Effects of parabolic flight and spaceflight on the endocannabinoid system in humans. Rev Neurosci. 2012;23:673-680.

29. Feuerecker M, Hauer D, Toth R, et al. Effects of exercise stress on the endocannabinoid system in humans under field conditions. Eur J Appl Physiol. 2012;112:2777-2781.

30. Hill MN, McEwen BS. Endocannabinoids: the silent partner of glucocorticoids in the synapse. Proc Natl Acad Sci U S A. 2009;106:4579-4580.

31. Heyman E, Gamelin FX, Goekint M, et al. Intense exercise increases circulating endocannabinoid and BDNF levels in humans-possible implications for reward and depression. Psychoneuroendocrinology. 2012; 37:844-851.

32. Lam PM, Marczylo TH, El-Talatini M, et al. Ultra performance liquid chromatography tandem mass spectrometry method for the measurement of anandamide in human plasma. Anal Biochem. 2008;380: 195-201.

33. Taylor AH, Amoako AA, Bambang K, et al. Endocannabinoids and pregnancy. Clin Chim Acta. 2010;411:921-930.

34. Miller GE, Chen E, Zhou ES. If it goes up, must it come down? Chronic stress and the hypothalamic-pituitary-adrenocortical axis in humans. Psychol Bull. 2007;133:25-45.

35. Tsigos C, Chrousos GP. Hypothalamic-pituitary-adrenal axis, neuroendocrine factors and stress. J Psychosom Res. 2002;53:865-871.

36. Chouker A, Kaufmann I, Kreth S, et al. Motion sickness, stress and the endocannabinoid system. PLoS One. 2010;5:e10752.

37. Patel S, Roelke CT, Rademacher DJ, et al. Endocannabinoid signaling negatively modulates stress-induced activation of the hypothalamicpituitary-adrenal axis. Endocrinology. 2004;145:5431-5438. 
38. Rademacher DJ, Meier SE, Shi L, et al. Effects of acute and repeated restraint stress on endocannabinoid content in the amygdala, ventral striatum, and medial prefrontal cortex in mice. Neuropharmacology. 2008;54:108-116.

39. Schmitt G, Herbold M, Peters F. Methodenvalidierung im forensischtoxikologischen. 1st ed. Labor. 2003.

40. Pragst F, Balikova MA. State of the art in hair analysis for detection of drug and alcohol abuse. Clin Chim Acta. 2006;370:17-49.

41. Russell E, Koren G, Rieder M, et al. Hair cortisol as a biological marker of chronic stress: current status, future directions and unanswered questions. Psychoneuroendocrinology. 2012;37:589-601.

42. Stalder T, Kirschbaum C. Analysis of cortisol in hair-state of the art and future directions. Brain Behav Immun. 2012;26:1019-1029.

43. Hamel AF, Meyer JS, Henchey E, et al. Effects of shampoo and water washing on hair cortisol concentrations. Clin Chim Acta. 2011;412:382-385.
44. Li J, Xie Q, Gao W, et al. Time course of cortisol loss in hair segments under immersion in hot water. Clin Chim Acta. 2011;413:434-440.

45. Gao W, Xie Q, Jin J, et al. HPLC-FLU detection of cortisol distribution in human hair. Clin Biochem. 2010;43:677-682.

46. Manenschijn L, Koper JW, Lamberts SW, et al. Evaluation of a method to measure long term cortisol levels. Steroids. 2011;76:1032-1036.

47. Thomson S, Koren G, Fraser LA, et al. Hair analysis provides a historical record of cortisol levels in Cushing's syndrome. Exp Clin Endocrinol Diabetes. 2010;118:133-138.

48. Pragst F, Yegles M. Determination of fatty acid ethyl esters (FAEE) and ethyl glucuronide $(\mathrm{EtG})$ in hair: a promising way for retrospective detection of alcohol abuse during pregnancy? Ther Drug Monit. 2008;30:255-263.

49. Hauer D, Weis F, Campolongo P, et al. Glucocorticoid-endocannabinoid interaction in cardiac surgical patients: relationship to early cognitive dysfunction and late depression. Rev Neurosci. 2012;23:681-690. 